\title{
Effect of Water on the Induction Period of the Polymerization of Methyl Methacrylate*
}

\author{
I. C. Schoonover, G. M. Brauer, and W. T. Sweeney
}

\begin{abstract}
The effect of water in monomer on the length of the induction period of the polymerization of methyl methacrylate was investigated for varying concentrations of water, catalyst, and inhibitor. For the benzoyl peroxide catalyzed polymerization, the induction period is markedly shortened by small quantities of water in the monomer. It is inversely proportional to the water concentration and directly proportional to the hydroquinone content. In the absence of inhibitor it is inversely proportional to the square root of the catalyst concentration. This acceleration effect is caused by the more rapid decomposition of benzoyl peroxide in water-containing monomer, with a subsequent slight increase in free radical concentration, which is sufficient to shorten the induction period. Water in the monomer does not alter appreciably the reaction rate after the induction period.
\end{abstract}

\section{Introduction}

The effect of impurities in the monomer on the length of the induction period and the kinetics of addition polymerization has been described by Bartlett and Altschul [1], ${ }^{1}$ Cohen [2], Ford [3], Kolthoff and Bovey [4, 5], Melville and Watson [6], Price and Read [7], and others. The effect of water on the polymerization of methyl methacrylate has not been reported in the literat ire. Since experiments in this Laboratory indicated that cast polymer made with methyl methacrylate containing water is more susceptible to crazing, the present work was undertaken to study the effect of water on the bulk polymerization of methyl methacrylate.

\section{Materials}

Commercial monomer (Rohm \& Haas) was purified by fractional distillation at $100-\mathrm{mm}$ pressure in a dry nitrogen atmosphere in an 8-in. column packed with glass helices. The purified monomer was stored in a refrigerator and was again fractionated immediately before use. This distillate had a refractive index $n_{D}^{25}$ of 1.4120 and a density $d_{4}^{25}$ of 0.93766 . Further fractionation did not change these physical constants. Tests showed that the distilled monomer contained less than 0.002 percent of free acid, less than 0.06 percent of water [8], and no peroxide [9] or hydroquinone [10].

Eastman Kodak reagent grades of benzoyl peroxide (approximately 97 percent pure), hydroquinone, and methyl $n$-butyrate, which was redistilled (bp 101.1 to $101.8^{\circ} \mathrm{C}$ ), were used without further purification.

\section{Procedure}

\subsection{Flow-Time Measurements}

Nitrogen was bubbled through the purified monomer for 10 to $15 \mathrm{~min}$, and benzoyl peroxide and hydroquinone were added. After dividing the sample into two parts, a measured amount of water

*Presented before the XIIth International Congress of Pure and Applied Chemistry, New York, September 1951.

${ } \mathrm{F}$ Figures in brackets indicate the literature references at the end of this paper. was added to one portion. Ten milliliters of each of the two samples was pipetted into calibrated Ostwald-Fenske viscometers. The viscometers were then placed in a constant-temperature bath maintained at $71.1^{\circ} \pm 0.1^{\circ} \mathrm{C}\left(160^{\circ} \mathrm{F}\right)$, and the time was noted. This time was taken as the start of the reaction. The viscometer openings were covered with tinfoil, and no effort was made to exclude oxygen. All viscometers were of the same size and had approximately the same air space above the liquid.

The flow time of the samples was measured at frequent intervals. The initial flow time of the monomer was $6.9 \mathrm{sec}(0.39 \mathrm{cps})$. Measurements were continued until a flow time of 100 sec was reached, which is equivalent to a polymer yield of 9 percent. All runs were repeated at least once. The reaction times for 100 -sec flow usually agreed within 10 percent. Uninhibited samples with catalyst concentrations below 0.01 percent showed larger variations, probably due to the presence of monomer peroxide.

No effort was made in this investigation to determine the exact length of the induction period, which may be defined as the time required to establish a steady-state concentration (equilibrium) of free radicals. Reaction times for 100 -sec flow are used in the subsequent discussions of the induction period. This corresponds to a relative flow time (defined as flow time of sample per flow time monomer) of 14.5. It is evident from the flow time versus reaction time curve that the induction period ends at an earlier reaction stage, probably in the neighborhood of 15-sec flow. Inspection of the data obtained showed that the reference point adopted did give the same quantitative relationship between water, catalyst, and inhibitor concentration and reaction time as earlier flow times and yielded more reproducible results.

\subsection{Benzoyl Peroxide Decomposition Measurements}

" Decomposition of benzoyl peroxide in methyl methacrylate and methyl $n$-butyrate was checked by both colorimetric and volumetric methods. 
For colorimetric determinations, volumetric flasks containing solutions of freshly distilled monomer and varying amounts of benzoyl peroxide were placed in a constant-temperature bath kept at $71.1^{\circ} \pm 0.1^{\circ} \mathrm{C}$ $\left(160^{\circ} \mathrm{F}\right)$. Periodically, $10-\mathrm{ml}$ samples were withdrawn, and the peroxide content was analyzed colorimetrically by the method suggested by Barnes [9].

To make volumetric determinations the benzoyl peroxide was dissolved in methyl $n$-butyrate (bp $101.1^{\circ}$ to $101.8^{\circ} \mathrm{C}$ ), and the solutions were stored in a constant-temperature bath kept at $71.1^{\circ} \pm 0.1^{\circ} \mathrm{C}$. Periodically, 2-ml samples were removed and analyzed by the method of Swain, Stockmeyer, and Clarke [11].

For decomposition measurements conducted in a nitrogen atmosphere the solution was placed in glass reaction vessels fitted with covers containing a gas-inlet tube, exit stopcock, and self-sealing stopper. Nitrogen was bubbled through the liquid for $20 \mathrm{~min}$. and the stopcocks were closed. Periodically, 2-ml samples were removed by means of a syringe and analyzed for benzoyl peroxide. Nitrogen was flushed through the apparatus at approximately $6-\mathrm{hr}$ intervals. The decomposition rate was followed until at least 50 percent of the benzoyl peroxide had decomposed.

\subsection{Infrared Measurements}

Infrared-absorption curves were obtained with a Perkin-Elmer double-beam recording spectrophotometer to check for the possible presence of a hydrated benzoyl peroxide complex.

\section{Results and Discussion}

The effect of water on the induction period of the methyl methacrylate polymerization is shown in table 1. Within experimental error, the time

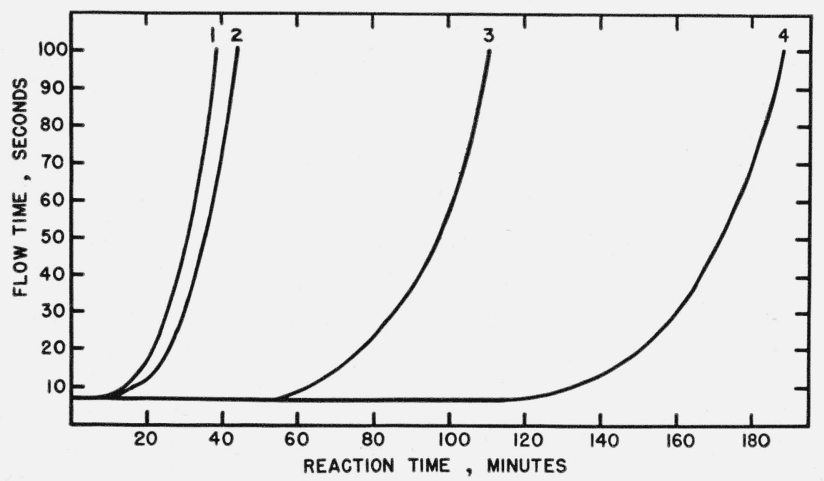

FIGURE 1. Effect of water on polymerization of methyl methacrylate with varying catalyst concentration.

\begin{tabular}{|c|c|c|}
\hline \multirow{2}{*}{ Curve } & \multirow{2}{*}{ Catalyst } & Water \\
& & \\
1 & g/liter & $\%$ \\
2 & 0.5 & 1 \\
3 & .5 & None \\
4 & .02 & 1 \\
4 & .02 & None \\
\hline
\end{tabular}

No inhibitor; temperature $71.1^{\circ} \mathrm{C}$.
TABLE 1. Effect of water on the induction period of the polymerization of methyl methacrylate

Catalyst concentration $0.02 \mathrm{~g} /$ liter of monomer

\begin{tabular}{|r|c|c|c|c|c|}
\hline \multirow{2}{*}{$\begin{array}{c}\text { Flow } \\
\text { time }\end{array}$} & \multicolumn{4}{|c|}{ Reaction time, and water content of monomer } \\
\cline { 2 - 6 } & $0 \%$ & $0.1 \%$ & $0.5 \%$ & $0.6 \%$ & $1.0 \%$ \\
\hline & & & & & \\
\hline sec & $\min$ & $\min$ & $\min$ & $\min$ & $\min$ \\
15 & 142 & 138 & 96 & 85 & 72 \\
25 & 155 & 150 & 108 & 102 & 83 \\
50 & 172 & 163 & 126 & 120 & 97 \\
100 & 188 & 179 & 143 & 135 & 110 \\
\hline
\end{tabular}

necessary to obtain a product of 100 -sec-flow decreases linearly with the quantity of water added. Table 2 lists the reaction time necessary to obtain a given flow time for the polymerization catalyzed by varying concentrations of benzoyl peroxide and water. Typical curves for reaction time versus flow time for anhydrous and water-containing samples are shown in figure 1 . In figure 2 the logarithm of the relative flow time is plotted versus the reaction time. The nearly identical slope of the logarithm of the relative flow time versus reaction time curves beyond a relative flow time of 4 indicates that the presence of water affects only the length of the induction period and not the subsequent polymerization rate. The time necessary to obtain a 100 -sec-flow product for anhydrous and water-containing monomer is inversely proportional to the square root of the catalyst, concentration (fig. 3). Thus the kinetics follow the usual course for the catalyzed addition polymerize. tion [12]. The effect of water decreases with increasing catalyst concentration and becomes negligible at concentrations greater than $1 \mathrm{~g} /$ 1iter.

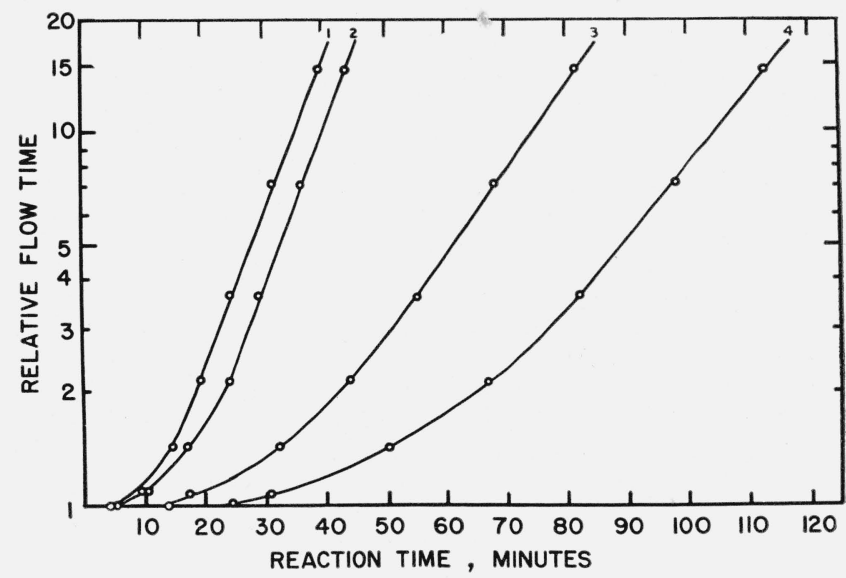

FIGURE 2. Effect of water on the polymerization of methyl methacrylate.

\begin{tabular}{|c|c|c|}
\hline Curve & Catalyst & Water \\
\cline { 1 - 2 } & $\begin{array}{c}\text { g/liter } \\
\text { minomer } \\
0.5\end{array}$ & $\%$ \\
1 & 1 \\
2 & .5 & None \\
3 & .06 & 1 \\
4 & .06 & None \\
\hline
\end{tabular}

Temperature $71.1^{\circ} \mathrm{C}$. 
TABLE 2. Effect of water and catalyst concentration on the induction period of the polymerization of methyl methacrylate

\begin{tabular}{|c|c|c|c|c|c|c|c|c|}
\hline \multirow{3}{*}{$\begin{array}{l}\text { Flow } \\
\text { time }\end{array}$} & \multicolumn{8}{|c|}{$\begin{array}{c}\text { Reaction time, and catalyst concentration in grams per liter } \\
\text { of monomer }\end{array}$} \\
\hline & \multicolumn{2}{|c|}{0.5} & \multicolumn{2}{|c|}{0.1} & \multicolumn{2}{|c|}{0.06} & \multicolumn{2}{|c|}{0.02} \\
\hline & $\begin{array}{c}\mathrm{No}_{2} \mathrm{O}\end{array}$ & $\begin{array}{c}1 \% \\
\mathrm{H}_{2} \mathrm{O}\end{array}$ & $\stackrel{\mathrm{No}_{2} \mathrm{O}}{\mathrm{H}^{2}}$ & $\begin{array}{c}1 \% \\
\mathrm{H}_{2} \mathrm{O}\end{array}$ & $\begin{array}{c}\mathrm{No}_{0} \\
\mathrm{H}_{2} \mathrm{O}\end{array}$ & $\begin{array}{c}1 \% \\
\mathrm{H}_{2} \mathrm{O}\end{array}$ & $\stackrel{\mathrm{No}}{\mathrm{H}_{2} \mathrm{O}}$ & $\begin{array}{c}1 \% \\
\mathrm{H}_{2} \mathrm{O}\end{array}$ \\
\hline $\begin{array}{c}s e c \\
7.5 \\
10 \\
15 \\
25 \\
50 \\
100\end{array}$ & $\begin{array}{c}\min \\
10 \\
17 \\
24 \\
29 \\
36 \\
43\end{array}$ & $\begin{array}{c}\min \\
9.5 \\
15 \\
19 \\
24 \\
31 \\
39\end{array}$ & \begin{tabular}{c}
$\min$ \\
\hdashline 54 \\
- \\
68 \\
80 \\
91
\end{tabular} & $\begin{array}{c}\min \\
19 \\
26 \\
36 \\
44 \\
55 \\
64\end{array}$ & $\begin{array}{r}\min \\
30 \\
50 \\
67 \\
82 \\
98 \\
113\end{array}$ & $\begin{array}{c}\min \\
17 \\
32 \\
44 \\
55 \\
68 \\
79\end{array}$ & $\begin{array}{l}\text { min } \\
-142 \\
155 \\
155 \\
172 \\
188\end{array}$ & $\begin{array}{r}\min \\
-72 \\
83 \\
97 \\
110\end{array}$ \\
\hline
\end{tabular}

Because in many polymerization reactions the hydroquinone inhibitor is not removed, a series of runs were conducted with varying concentrations of inhibitor, water, and catalyst. The effect of hydroquinone on the length of the induction period of anhydrous and water-containing monomer is shown in table 3. In figure 4 is shown the linear increase of the induction period with increasing inhibitor concentration. This proportionality of induction period and hydroquinone probably indicates a stoichiometric relationship between inhibitor and free radicals.

The presence of hydroquinone not only influences the length of the induction period, but also acts as a retarder (fig. 5). Even after completion of the induction period, the rate of polymerization is considerably less than in the absence of inhibitor. This retardation increases as the initial concentration of inhibitor is increased. Similar results were obtained in the quinone inhibited polymerization [13]. This effect may be due to the fact that (1) the polymerization begins while some hydroquinone is still

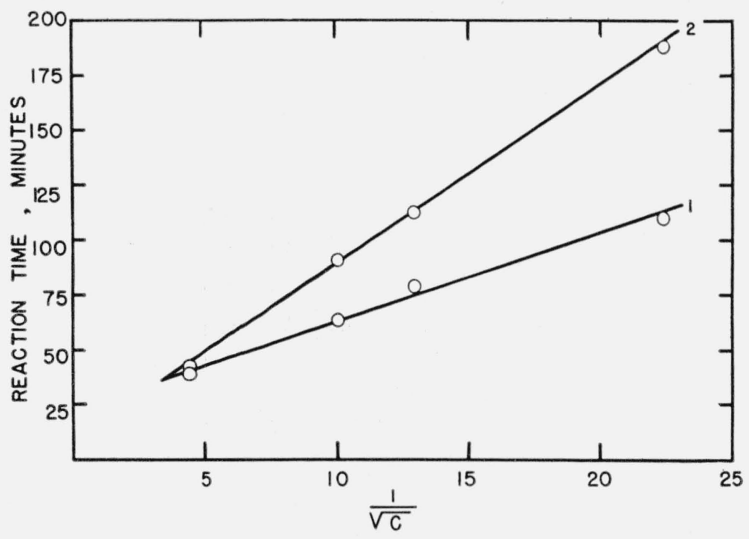

Figure 3. Effect of water and catalyst on methyl methacrylate polymerization.

\begin{tabular}{|c|c|}
\hline Curve & Water \\
\cline { 2 - 2 } & \\
& $\%$ \\
1 & 1 \\
2 & None \\
\hline
\end{tabular}

C, catalyst concentration, $\mathrm{g} / 100 \mathrm{ml}$ of monomer; flow time, 100 seconds; temperature, $71.1^{\circ} \mathrm{C}$.
TABLE 3. Effect of hydroquinone and water on the induction period in the polymerization of methyl methacrylate

Benzoyl peroxide concentration $2.5 \mathrm{~g}$ /liter of monomer

\begin{tabular}{|c|c|c|c|c|c|c|c|c|}
\hline \multirow{3}{*}{$\begin{array}{l}\text { Flow } \\
\text { time }\end{array}$} & \multicolumn{8}{|c|}{$\begin{array}{c}\text { Reaction time, and hydroquinone concentration in grams per } \\
\text { liter of monomer }\end{array}$} \\
\hline & \multicolumn{2}{|c|}{0.03} & \multicolumn{2}{|c|}{0.06} & \multicolumn{2}{|c|}{0.09} & \multicolumn{2}{|c|}{0.15} \\
\hline & No $\mathrm{H}_{2} \mathrm{O}$ & $1 \% \mathrm{H}_{2} \mathrm{O}$ & $\mathrm{No}_{2} \mathrm{O}$ & $1 \% \mathrm{H}_{2} \mathrm{O}$ & $\mathrm{No} \mathrm{H}_{2} \mathrm{O}$ & $1 \% \mathrm{H}_{2} \mathrm{O}$ & $\mathrm{No} \mathrm{H}_{2} \mathrm{O}$ & $1 \% \mathrm{H}_{2} \mathrm{O}$ \\
\hline $\sec$ & $\min$ & $\min$ & $\min$ & $\min$ & $\min$ & $\min$ & $\min$ & $\min$ \\
\hline 7.5 & 40 & 23 & 68 & 32 & 84 & 34 & 126 & 41 \\
\hline 10 & 46 & 30 & 78 & 41 & 100 & 46 & 162 & 61 \\
\hline 15 & 52 & 35 & 88 & 48 & 115 & 58 & 196 & 85 \\
\hline 25 & 58 & 40 & 100 & 58 & 132 & 74 & 224 & 105 \\
\hline 50 & 67 & 48 & 114 & 70 & 150 & 92 & 258 & 132 \\
\hline 100 & 75 & 56 & 127 & 82 & 169 & 108 & 285 & 158 \\
\hline
\end{tabular}

present, and (2) the inhibition products are not inert toward radicals, that is, they in turn influence the polymerization.

The length of the induction period is inversely proportional to the percentage of water initially in the monomer (fig. 6). In the polymerization with $0.5 \mathrm{~g} /$ liter benzoyl peroxide and $0.06 \mathrm{~g} /$ liter hydróquinone a $100-$ sec flow is reached after $700 \mathrm{~min}$. A similarly prepared sample containing 1 percent of water reaches this flow within $370 \mathrm{~min}$.

The effect of water on the induction period decreases rapidly with increasing catalyst and decreasing inhibitor content (see figs. 4 and 7). Extrapolation to zero hydroquinone concentration gives for anhydrous and 1 percent water-containing monomer to which $2.5 \mathrm{~g} /$ liter catalyst has been added a reaction time of $31 \mathrm{~min}$ for the formation of a 100 -sec-flow polymer. This is in excellent agreement with extrapolated values from curves of the reaction time versus square root of catalyst concentration for uninhibited monomer.

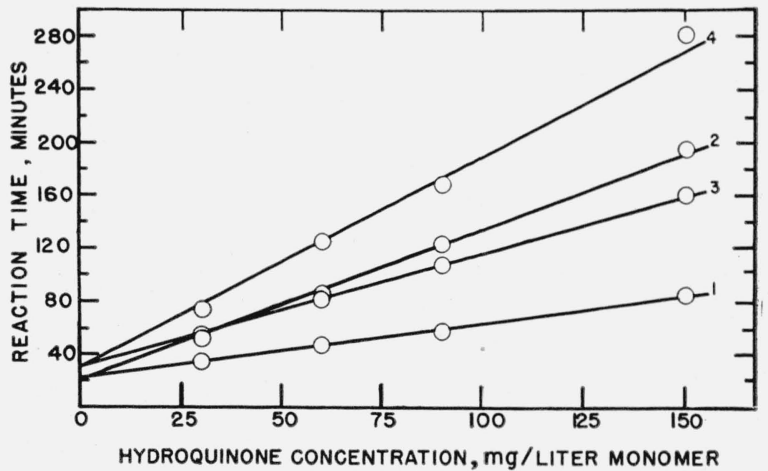

Figure 4. Effect of water and inhibitor on the induction period of the polymerization of methyl methacrylate.

\begin{tabular}{|c|c|c|}
\hline Curve & $\begin{array}{c}\text { Flow } \\
\text { time }\end{array}$ & Water \\
\cline { 1 - 1 } & & \\
\cline { 1 - 1 } 1 & sec & $\%$ \\
15 & 1 \\
2 & 15 & None \\
3 & 100 & 1 \\
4 & 100 & None \\
\hline
\end{tabular}

Catalyst concentration, $2.5 \mathrm{~g} /$ liter of monomer; temperature, $71.1^{\circ} \mathrm{C}$. 


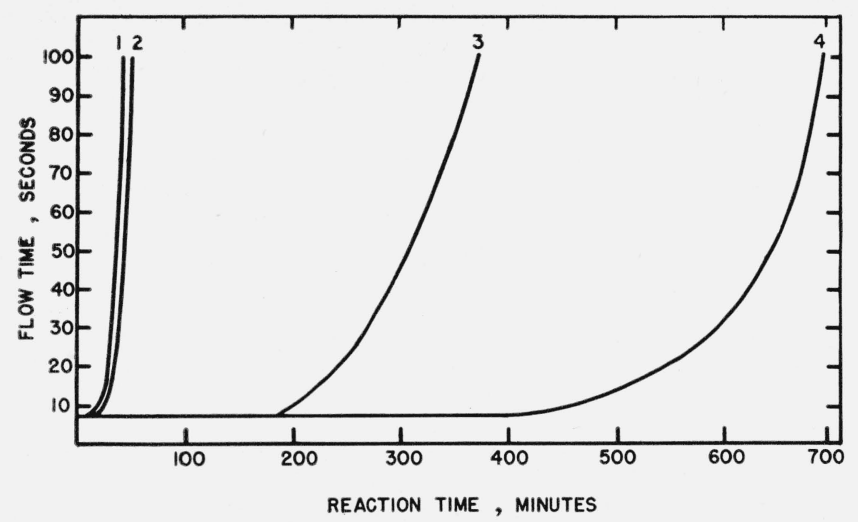

FIGURE 5. Effect of water on polymerization of methyl methacrylate with and without inhibitor.

\begin{tabular}{|c|c|c|}
\hline Curve & Inhibitor & Water \\
\cline { 3 - 4 } & & \\
1 & olluter & $\%$ \\
$\mathbf{2}$ & none & 1 \\
$\mathbf{3}$ & 0.06 & None \\
$\mathbf{4}$ & .06 & 1 \\
& & \\
\end{tabular}

Catalyst $0.5 \mathrm{~g} /$ liter; temperature $71.1^{\circ} \mathrm{C}$.

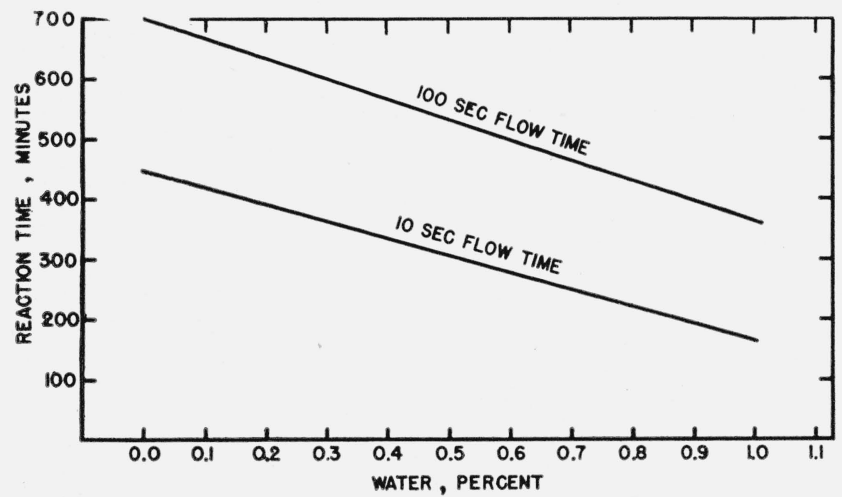

FIGURE 6. Effect of water on polymerization of methyl methacrylate.

Temperature $71.1^{\circ} \mathrm{C}$; catalyst $0.5 \mathrm{~g} /$ liter of monomer; inhibitor, $0.06 \mathrm{~g} /$ liter of monomer.

Figure 8 shows the polymerization rate curves for hydroquinone-inhibited monomer containing 0.5 and $7.5 \mathrm{~g}$ of benzoyl peroxide per liter of monomer. With inhibitor no simple relationship was found between peroxide content and induction period covering the entire catalyst concentration range investigated. At concentrations above $1 \mathrm{~g} /$ liter the 100 -sec-flow value is inversely proportional to the initial catalyst concentration (fig. 7), that is, the rate determining step during the induction period is probably second order with respect to catalyst, although the kinetics are complicated by the fact that the presence of hydroquinone or its conversion products accelerate the peroxide decomposition [2]. At catalyst concentrations below $1 \mathrm{~g} /$ liter, where the catalyst-inhibitor ratio is small, the effect of hydroquinone becomes so pronounced that it alters the kinetics of the reaction.

Measurements of the effect of water on the induction period in the absence of catalyst (thermal poly-

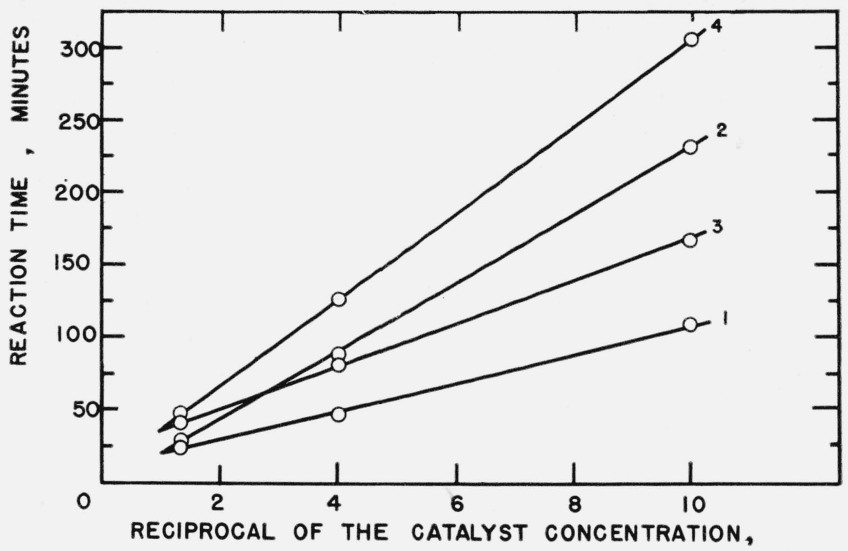

$(\mathrm{g} / 100 \mathrm{ml} \text { MONOMER })^{-1}$

Figure 7. Effect of water and catalyst on the induction period of the polymerization of methyl methacrylate.

\begin{tabular}{|c|c|c|}
\hline Curve & $\begin{array}{c}\text { Flow } \\
\text { time }\end{array}$ & Water \\
\cline { 1 - 2 } & sec & $\%$ \\
1 & 15 & 1 \\
2 & 15 & None \\
3 & 100 & 1 \\
4 & 100 & None \\
\hline
\end{tabular}

Hydroquinone concentration, $60 \mathrm{mg} /$ liter of monomer; temperature, $71.1^{\circ} \mathrm{C}$.

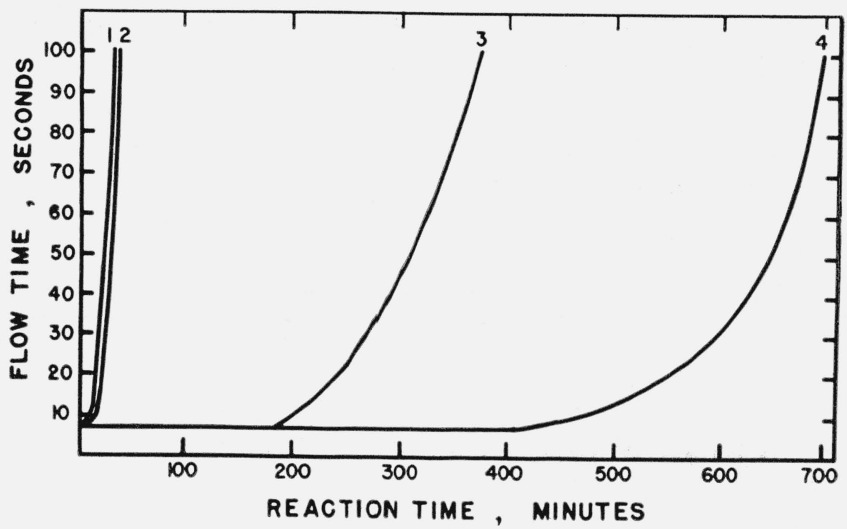

FIGURE 8. Effect of water on polymerization of methyl methacrylate with varying catalyst concentration.

\begin{tabular}{|c|c|c|}
\hline \multirow{2}{*}{ Curve } & Catalyst & Water \\
\cline { 1 - 2 } & & \\
\cline { 1 - 2 } & g/liter & $\%$ \\
1 & 7.5 & 1 \\
2 & 7.5 & None \\
3 & 0.5 & 1 \\
$\mathbf{4}$ & .5 & None \\
& &
\end{tabular}

Inhibitor $0.06 \mathrm{~g} /$ liter; temperature $71.1^{\circ} \mathrm{C}$.

merization) are within the limits of experimental error. The time in which 100 -sec-flow products were attained varied from 254 to $265 \mathrm{~min}$ for anhydrous and water-containing samples. The induction period and rate of the thermal polymerization are influenced to a large extent by traces of impurities. Air initially present retards the polymerization of anhydrous and water-containing samples. A 20percent increase in the length of the induction period 
and a considerable decrease in the polymerization rate were observed due to preferential reactivity of the activated monomer with oxygen.

Because the induction period of the thermal polymerization remains constant in the presence of water, the observed change of the induction period for the catalyzed reaction must be due to an increase in the decomposition rate of peroxide in aqueous media at low catalyst concentrations. Hence, more free radicals, that will act as polymerization initiators will be formed in the presence of water.

To check further the effect of water, the peroxide decomposition rate was measured by comparing colorimetrically the peroxide concentration of monomer that had been kept at $71.1^{\circ} \mathrm{C}$ for various periods of time. A slight but noticeable increase in the decomposition rate was observed in monomer containing 1 percent of water. Because at this elevated temperature decomposition measurements in monomer are difficult to conduct due to the small amount of catalyst that must be used to obtain an appreciable induction period, more accurate determinations with $0.05 M$ benzoyl peroxide in methyl $n$-butyrate (a prototype of methyl methacrylate that does not polymerize) were conducted. An increase of approximately 30 percent in the reaction rate constants for water-containing solutions was observed.

When decomposition rates were determined in a nitrogen atmosphere, the reaction was not appreciably accelerated by 1 percent of water. Thus oxygen is necessary for the acceleration of the peroxide decomposition by water. First-order kinetics indicative of a free radical mechanism were observed up to 50-percent decomposition. The first-order rate constants for a reaction time up to 20 $\mathrm{hr}$ (approximately 50-percent decomposition) calculated by the method of least squares amounts to $0.0341 \mathrm{hr}^{-1}$ and $0.0378 \mathrm{hr}^{-1}$ for anhydrous and watercontaining solutions, respectively. This difference in rate constants is not considered significant. Large deviations from these rate constants in the later stages of the decomposition are due to (1) the effect of the presence of reaction products formed, (2) slight losses due to evaporation, and (3) possible presence of traces of oxygen in the solution.

The length of the induction period with the more efficient 2-azo-bis-isobutyronitrile catalyst is also shortened with water-containing monomer.

Addition of $\mathrm{D}_{2} \mathrm{O}$ to monomer results in an induction period approximately equal to that of monomer containing the same percentage of $\mathrm{H}_{2} \mathrm{O}$. Thus, within the limits of the experimental error (10 percent), no isotope effect is observed. Water seems to speed up the catalyst decomposition only and apparently does not affect the chain propagation and termination reaction.

It has been reported by a number of investigators that not only the rate but also the stoichiometry of the decomposition of benzoyl peroxide varies from solvent to solvent as well as with the peroxide concentration initially present $[14,17]$. Because highest decomposition rates have been observed in highly polar associated solvents, such as phenols, amines, alcohols, and acids $[11,14,15,16]$, an increase in the presence of water should be expected.

If the decomposition proceeds by the mechanism previously postulated $[16,17]$ :

$$
\begin{array}{ll}
\text { A } & \left(\mathrm{C}_{6} \mathrm{H}_{5} \mathrm{COO}\right)_{2} \underset{k_{1}}{\longrightarrow} 2 \mathrm{C}_{6} \mathrm{H}_{5} \mathrm{COO} . \\
\text { B } & \mathrm{C}_{6} \mathrm{H}_{5} \mathrm{COO} \cdot+\mathrm{RH} \underset{k_{2}}{\underset{\mathrm{C}}{\longrightarrow}} \mathrm{C}_{6} \mathrm{H}_{5} \mathrm{COOH}+\mathrm{R} . \\
\mathrm{C} & \mathrm{R} \cdot+\left(\mathrm{C}_{6} \mathrm{H}_{5} \mathrm{COO}\right)_{2} \underset{k_{3}}{\longrightarrow} \mathrm{C}_{6} \mathrm{H}_{5} \mathrm{COO} \mathrm{R}+\mathrm{C}_{6} \mathrm{H}_{5} \mathrm{COO} .
\end{array}
$$

The results suggest that the benzoyl radical favors capture of the hydrogen of the polar water molecule instead of fission of covalent $\mathrm{C}-\mathrm{H}$ bonds. The $\mathrm{OH}$ radical formed will react with benzoyl radicals to give perbenzoic acid instead of a benzoic acid ester which is formed if a $\mathrm{C}-\mathrm{H}$ bond is cleaved. This peracid readily decomposes into free radicals that will also speed up the peroxide decomposition. Hence, the more readily the benzoyl radical can react with $\mathrm{RH}$, the greater the speed of reaction.

From the detailed studies of the kinetics of the methyl methacrylate polymerization, Schulz and coworkers $[18,19]$ assumed that catalyst and monomer exist in equilibrium with a complex that rearranges to give the first radical unit in the growing chain, but no independent evidence of this complex was reported. The increased rate of decomposition of catalyst observed in mixtures of benzene and vinyl acetate as compared with the rate in benzene alone [20], as well as the changing stoichiometry of the decomposition of finite concentrations of benzoyl peroxide in benzene [2], has also been ascribed to the formation of some intermediate complex, possibly $\left(\mathrm{C}_{6} \mathrm{H}_{5} \mathrm{COO}\right)_{2} \cdot \mathrm{C}_{6} \mathrm{H}_{6}$, in a preliminary, rapidly reversible step. These data, as well as the present results, suggest that a hydrated peroxide complex formation takes place in the presence of water, with the subsequent rapid decomposition of this thermally unstable intermediate. However, polymerization of samples of monomer containing equivalent amounts (based on peroxide) of reagent grade and hydrated benzoyl peroxide (approximately 12 percent of water) show that such a hydrate does not appreciably decrease the length of the induction period. Furthermore, the absence of hydrated peroxide complexes at room temperature was established from a series of infrared-absorption measurements of 1.5percent solutions of benzoyl peroxide in chloroform containing 0.15 percent of water.

The more rapid decomposition can also be explained in terms of the "cage effect" as postulated by Matheson [21]; that is, two fragments from the dissociated molecule find themselves held in a cage of solvent molecules, and therefore the radical pairs collide many times with each other and with the surrounding molecules before they can diffuse apart. The water may presumably permit diffusion to occur more rapidly. On the other hand, the water may be effective in reducing the activation energy of the reaction between radical and monomer. 


\section{Summary}

1. The length of the induction period of the benzoyl peroxide catalyzed polymerization of methyl methacrylate is markedly shortened at low catalyst concentrations by the presence of water in the monomer.

2. The length of the induction period is inversely proportional to the water concentration and directly proportional to the hydroquinone concentration in the monomer. In the absence of inhibitor, it is inversely proportional to the square root of the catalyst concentration.

3. Presence of water in the monomer does not appreciably alter the reaction rate after the induction period.

4. As a slight increase in free radical concentration will shorten the induction period, the more rapid decomposition of benzoyl peroxide in water-containing monomer causes these effects. Possible mechanisms of this effect have been suggested.

\section{References}

[1] P. D. Bartlett and R. Altschul, J. Am. Chem. Soc. 67, 812 (1945).

[2] S. G. Cohen, J. Am. Chem. Soc. 69, 1057 (1947); J. Polymer Sci. 2, 511 (1947).
[3] S. G. Ford, J. Chem. Soc. 48 (1940).

[4] F. A. Bovey and I. M. Kolthoff, Chem. Rev, 42, 491 (1948).

[5] I. M. Kolthoff and F. A. Bovey, J. Am. Chem. Soc. 70, 791 (1948)

[6] H. W. Melville and W. F. Watson, Trans. Faraday Soc. 44, 886 (1948).

[7] C. C. Price and D. H. Read, J. Polymer Sci. 1, 44 (1946).

[8] F. W. Zerban and L. Sattler, Anal. Chem. 18, 138 (1946).

[9] C. E. Barnes, J. Am. Chem. Soc. 67, 217 (1945).

[10] E. Eegriwe, $Z$. anal. Chem. 125, 241 (1943).

[11] C. G. Swain, W. H. Stockmayer, and J. T. Clarke, J. Am. Chem. Soc. 72,5426 (1950).

[12] R. Houwink, Elastomers and plastomers. General theory, I, p. 105 (Elsevier Publishing Co., Inc., 1950).

[13] G. M. Burnett and H. W. Melville, Proc. Roy. Soc. (London) [A] 189, 481 (1947).

[14] B. Barnett and W. E. Vaughan, J. Phys. \& Colloid Chem. 51, 926, 942 (1947).

[15] H. Gelissen and P. H. Hermans, Ber. deut. chem. Ges. 58B, 765 (1925).

[16] K. Nozaki and P. D. Bartlett, J. Am. Chem. Soc. 68, 1686 (1946); J. Am. Chem. Soc. 69, 2299 (1947).

[17] W. E. Cass, J. Am. Chem. Soc. 68, 1976 (1946).

[18] G. V. Schulz and E. Husemann, $Z$. physik. Chem. [B] 39, 246 (1939).

[19] G. V. Schulz and F. Blaschke, Z. physik. Chem. [B] 51, 75 (1942).

[20] S. Kamenskaya and S. Medvedev, Acta. Physicochim. U. R. S. S. 13, 565 (1940).

[21] M. S. Matheson, J. Chem. Phys. 13, 584 (1945).

Washington, September 5, 1952. 